\title{
The Predicament of Inclusive Education and the Realities of Practice in Tanzania after Two Decades of Education for All
}

\author{
Orestes Silverius Kapinga, ${ }^{1, *}$ \\ ${ }^{1}$ Faculty of Education, Mkwawa University College of Education, P.O. Box 2513, Iringa, \\ Tanzania \\ *Correspondence: Tel: 255-769-762-641 E-mail: orestes.katopu@gmail.com
}

Received: October 6, 2014 Accepted: December 4, 2014 Published: December 21, 2014

doi:10.5296/ije.v6i4.6424 URL: http://dx.doi.org/10.5296/ije.v6i4.6424

\begin{abstract}
Tanzania has been implementing several educational development plans and programmes at primary and secondary education levels. These plans and programmes aim at realizing the goal of education for all and therefore making primary education and ordinary secondary education universal. The implementation of these plans and programmes reflects a substantial need for educators and professionals in special education who can be able to handle pupils in inclusive and special classrooms and schools. The aim of the present study was to explore the participants' motives for participating in a B.Ed. Special Education programme and the perceived outcomes of the programme in terms of professional development. The study focused on two core issues: motives and perceived outcomes. A case study approach was adopted. Questionnaires and interviews were administered in three phases between January 2007 and February 2009 to a group of 35 educators participating in a B.Ed. Special Education programme.

Findings of the study revealed that participants expressed a number of motives and outcomes related to job, degree and career, student and community support, and personal growth. The findings further confirm that the participants' motives and outcomes were closely related. The findings serve as a starting point for discussing the phenomenon of professional development in special education in Tanzania. Furthermore, the study findings underline that the motives for participating in the programme were complex, interactive and dynamic, thus emphasis on a singular explanation is naïve and insufficient.
\end{abstract}

Keywords: inclusive education; special education; professional development; case study; Tanzania 


\section{Introduction}

The commitment to provide primary education to every child is the oldest of the Millennium Development Goals, having been set at the first Education for All conference in Jomtien, Thailand more than 20 years ago. There are today several primary and secondary schools in Tanzania that are involved in inclusive education programmes. The significance of inclusive education has been recognized at the educational policy level in Tanzania. The government of the United Republic of Tanzania has been committed to Universal Primary Education since 1977 when enrolment rates reached 95\%, but the economic hardship of the 1980s eroded these gains. In response to the economic problems, the Government introduced cost-sharing measures, froze recruitment of teachers and reduced overall spending on education. These measures led to a shortage of teaching and learning materials, non-maintenance of school infrastructure, discontinued classroom construction, as well as a shortage of teachers. These effects resulted in low enrolment, high dropout rates, low performance at national examinations, dilapidated buildings, an uncomfortable learning environment and a decline in completion rates. The Education Act No. 25 of 1978 made primary education compulsory though not free (Okkolin, Lehtomäki \& Bhalalusesa, 2010).

The projected population in Tanzania for the 2012 Population and Housing Census conducted in August 2012 was 45 million people (URT, 2012). There are an estimated four million people living with disabilities in Tanzania(Note 1). What does it mean in terms of education provision for persons with disabilities? The growing population suggests more expansion in school enrolment and facilities for persons with disabilities. This has also implications on teacher deployment and further development.

Primary schools and secondary schools accommodating pupils with disabilities in Tanzania face many challenges. Most of the classrooms are crowded with large number of pupils. The classrooms have poor conditions with an acute shortage of furniture. On average about five pupils share one desk, and majority of the pupils sitting on the floor. Most schools especially in the rural areas are understaffed. The pupil qualified teacher ratio (PQTR) is high. For example, the PQTR in primary schools in 2013 was 1:44, Geita region having the highest PQTR (MoEVT, 2013). In secondary schools, the PQTR for 2013 was 1:28. Considerable variations exist between schools and between regions, some having a PQTR of 1:82 or higher, much higher than the national target of 40 pupils per classroom. The Secondary School standard of PQTR is $1: 40$ per subject. Though PQTR (1:28) are more than the standard (1:40) still there is a shortage of qualified teachers per subject especially Science Subjects (MoEVT, 2013). Most pupils lack basic learning materials such as books, pens and pencils. The average pupil to textbook ratio is 5 to 1 . Schools have poor sanitation facilities. Most schools lack clean and safe drinking water as well as playgrounds for sports activities. The pupil to latrine ratio is 90:1, meaning that 90 pupils have to use one pit latrine/pit toilet. Schools are not designed to cater for children with disabilities and teachers are not adequately trained. Generally, the learning environment is unfriendly and not supportive for pupils with disabilities. What is the situation of a child with disability in the absence of teachers with some knowledge in special education? This account implies that the situation for pupils with special needs included in the regular classrooms is threatening and that pupils with disabilities are the most underprivileged. 
The Primary Education Development Plan I (PEDP I) 2002-2006 was the first outcome of the efforts to turn international education obligations into feasible strategies and actions followed by PEDP II (2007-2011). However, the impact of the introduction of free education in 2002 is evident in the increase in net enrolment rates from $58.6 \%$ in 2000 to $96.1 \%$ in 2006 . The net enrolment in primary schools for 2010 was 8,419,305 and for 2013 stood at $89.7 \%$ (MoEVT, 2011; MoEVT, 2013). Trends in enrolment show that the number of pupils with disabilities in primary schools increased from 18982 in 2006 to 26436 in 2011 and dropped to 24584 in 2013. The enrolment rates for pupils with disabilities have increased but not significantly. Population data on disability is not available, but the proportion of primary school enrolment for pupils with disabilities is $0.3 \%(24,584$ out of $8,231,913)$ in 2013 (MoEVT, 2013). This proportion is low mainly due to low response of the community in sending pupils with disability to school.

The Secondary Education Development Programme (SEDP I \& II) paid attention to students with disabilities, though there were no specific objectives and strategies of making education more accessible for pupils with disability (URT, 2004; O-Saki \& Njabili, 2003). Educational services to persons with disability have increased significantly during the last two decades, but they still are inadequate and of poor quality (Mboya \& Mosha, 2003). Enrolment in secondary schools for persons with disability increased from 716 in 2006 to 5534 in 2010 and dropped to 5008 in 2011. In 2010 there were 39 secondary schools enrolling students with disability in the disability categories of albinism and low vision, autism, hearing impairments, visual impairments, deaf blindness, intellectual impairments, multiple impairments, physical impairments and others.

The increasing enrolment of pupils with disabilities suggests that there is a need for more teachers with higher and relevant qualifications in special education who can meet the demand for teachers in both regular and special schools and classrooms. Professional development in special education is one strategy of addressing the growing demand for teachers in schools with a background in special education. The two massive educational programmes (PEDP \& SEDP) have mentioned very little about special education and how pupils with special needs are catered for in the programmes (MoEC, 2001; MoEC, 2004; MoEVT, 2006; MoEVT, 2010). The implication is that schools for children with special needs have in fact never been accepted in the general education system and are not included in official policies.

In most schools in Tanzania, the significantly increased enrolment rates at Standard I have resulted in overcrowding, and children repeating years have further aggravated the problem. According to previous studies, lack of qualified and competent teachers is one factor attributed to increased repetition rates. The repetition rate is higher in the lower grades and decreases in higher grades (Kalanje, 2011). The available statistics indicate that the level of passing examinations for pupils with disabilities is falling. For instance, in year 2009 only $65 \%$ of pupils with disabilities were selected to join secondary schools comparing to $70.43 \%$ of 2008 . Therefore, for one year the number had fallen for about $16 \%$. This situation is expected to be worsened, as the condition in schools has not improved.

Reports and experience show that people with disabilities often face mistreatments in a number of ways and because of various reasons. For instance, according to Legal and Human Rights 
Centre's Report (Tanzania Human Rights Report of 2008), the World Bank has estimated that, $20 \%$ of the most impoverished individuals are disabled because they lack education and employment opportunities to earn their living. A Disability Survey Report of the Government of the United Republic of Tanzania conducted by the National Bureau of Statistics in 2008 found disability prevalence to be $7.8 \%$ (about 2.4 million people) (URT, 2008). The survey also reported that, the illiteracy rate for persons with disabilities in Tanzania was $47.6 \%$ compared to $25.3 \%$ of the persons without disabilities. That means almost half of the persons with disabilities are not educated. The survey also revealed that $15.5 \%$ of children with disabilities aged between 3-14 years were refused entry to schools because of their disabilities. The highest refusal of $8.4 \%$ was in regard to entry into regular primary schools. This was followed by refusal to join the regular pre-schools at $4.7 \%$ (URT, 2008).

\subsection{Challenges in enhancing inclusive education}

Although, there are quite a few schools currently offering education in inclusive settings, especially through the Government's programme, the challenges to further develop inclusive education in the Tanzanian primary and secondary schools are immense. One major challenge is related to the supply of enough and qualified teachers with a background in special education who can teach in the regular classrooms and schools which accommodate pupils with special needs. In this view, inclusive education is one major explanation to reach majority of the children with disabilities in schools. One way of enhancing this is through the professional development of teachers and educators who can teach and conduct research.

\subsection{Teacher education in Tanzania}

Teacher education in Tanzania is categorized as regular and special education teacher education. Both regular and special education teacher education is college based and university based, and similarly both systems offer pre-service and in-service teacher education programmes. The college-based regular teacher education programmes offer a two-year grade ' $A$ ' teacher education certificate and diploma in education. Teacher grade ' $A$ ' certificate is the initial course for primary school teachers and it is the minimum qualification for teaching at primary school level. A diploma in education is the initial qualification for teaching in secondary schools. In 2010, the enrolment in both Government and Non-Government Teacher Colleges was 36,648, of which the enrolment for teachers in special education was $0.8 \%$ equivalent to about 290 student teachers (MoEVT, 2011). The University based regular teacher education programmes offer a three-year bachelor's degree, which qualifies graduates for teaching in advanced level secondary schools and teachers' colleges. There are at present 28 universities and university colleges which offer degree programmes in education. Of the 28 universities and university colleges, only two universities and one University College offer degree programmes in special education at a bachelor's level.

The college based teacher education for special education is offered at one teachers' college (Patandi Teachers' College). The college offers programmes at certificate and diploma levels. These are the teachers expected to work in special primary and secondary schools respectively. The teacher education for special education is categorical in character, that is, student teachers specialize and become experts in one disability area. Three areas of specialization are offered at 
Patandi: visual impairment, hearing impairment and intellectual impairment. Some disability areas such as autism, deaf blindness, learning disabilities, speech and language disorders, physical disabilities, emotional and behavioural disorders, health impairments and multiple disabilities are not offered as specialisations. The capacity of Patandi is to enrol around 300 student teachers per year. This number is extremely small to meet the ever-growing demand for teachers with qualifications in special education countrywide.

To meet the demands of teachers and educators with specialization in special education, and with a degree qualification, the Open University of Tanzania (OUT) introduced the first bachelor's programme in special education in 2005 in cooperation with Åbo Akademi University. This was an in-service programme for teachers and professionals in special education. The first batch of the B. Ed. Special Education programme was offered as a pilot. The programme was later mainstreamed into the OUT's wide programmes. The Sebastian Kolowa University College (SEKUCo) recently transformed into a full-fledged university, Sebastian Kolowa Memorial University (SEKOMU) started offering a three-year bachelor's degree in special needs education (B. EdSN) in October 2007. The university enrols both fresh entrants and those with a background in special education. The bachelor's programme is offered in the following specializations: cognitive disabilities and autism spectrum, visual impairments, hearing impairments, and speech and language disabilities. Disability areas such as deaf blindness, health impairments, physical disabilities and emotional and behavioural disorders are not catered for. The University of Dodoma since 2009 offers a three year Bachelor of Education in Special Needs (B.Ed. SPED) for both pre-service and in-service teachers. It is however, important to note that teacher education for special education has been very limited in quantity.

\subsection{Aim and relevance of the study}

Given this scenario, it was considered important to explore the motives of the participants in a B.Ed. Special Education programme and their perceived outcomes of the programme in terms of professional development. In my study, I have focused on motives and perceived outcomes, and how the motives relate to the perceived outcomes. One may ask the following questions: Why was it important for me to conduct a study with a focus on a degree programme? And why was it important to specifically explore the participants' motives and perceived outcomes?

First, as Tanzania has only one college of teacher education for special education, the need for university based programmes in special education is obvious. Furthermore, the basic training which teachers get through initial teacher education programmes does not provide them with adequate theoretical and practical experiences related to special education. It was therefore important to explore the motives held by participants for participating in the programme and their perceived outcomes of the programme. Second, the in-service education and training (INSET) provision for teachers in Tanzania is inadequate in terms of coordination, consistency and coverage. This study focused on a group of participants in the B.Ed. Special Education programme as this was the first bachelor's programme in special education to be offered in Tanzania. Thus, exploring motives and perceived outcomes would enable me to make valid conclusions of what kind of motives can be held by teachers and educators in the general 
education. Third, little or no research on teachers' professional development in special education has been conducted in Tanzania. This study has attempted to explore educators' motives and their perceived outcomes in terms of professional development in an attempt to fill the knowledge gap in the field. The topic was chosen for the reason of the lack of theoretical and practical knowledge of the professional development phenomenon in special education in Tanzania. The findings may therefore serve as a starting point for discussing the phenomenon of professional development for teachers and educators in special education in Tanzania.

\section{Theoretical considerations}

In establishing the theoretical foundations for the study, three theoretical perspectives were in focus. They are: individual, social and societal perspectives. The choice of the three perspectives is based on the assumption that professional development phenomenon is seen as interplay between individual, social and societal factors. Therefore, professional development is viewed as an individual, social and societal phenomenon.

The individual perspective emphasizes psychological factors such as motives, motivation, achievement, self-directed behaviour and personal growth. Deci and Ryan (1985) proposed a self-determination continuum to describe motivational variables with different degrees of self-determination. From higher to lower self-determination, Deci and Ryan (1985) identified three types of motivation, namely intrinsic motivation, extrinsic motivation and amotivation. Intrinsically motivated behaviours are those that are engaged in for their own sake, in other words, for the pleasure and satisfaction derived from performing them (Deci, 1971). Extrinsic motivation refers to activities that are carried out as a means to an end and not for their own sakes (Deci, 1975). According to Deci and Ryan (2002) extrinsic motivation refers to a broad array of behaviours having in common the fact that activities are engaged in not for reasons inherent in them but for instrumental reasons. The third type is amotivation, or lack of intrinsic or extrinsic motivation. Amotivation represents the absence of self-determination (Levesque, Copeland \& Sutcliffe, 2008). When amotivated, individuals disengage from the activity and eventually stop doing it. Amotivation according to Ryan and Deci (2000) results from perceptions of helplessness or lack of self-efficacy, competence or valuation of the activity. According to Ryan and Deci (2000) people have not only different amounts, but also different kinds of motivation. That is, different people have different orientations of motivation - intrinsic or extrinsic - as well as different levels of motivation.

The social perspective stresses the central role played by the social and cultural factors in learning and development. The social perspective focuses on interaction among and between people as a primary source of knowledge that cannot be gained in isolation from other people (Howe \& Stubbs, 1996). The societal perspective is related to factors such as transformation of the education system, awareness of disability issues and change. Societal perspective proposes that education is a form of political intervention in the world that is capable of creating the possibilities for social transformation (Giroux, 2004). 


\section{Methods}

The overall aim of the present study was to explore participants' motives for participating in a B. Ed programme in special education and the perceived outcomes of the programme in terms of professional development. The study adopted a descriptive case study as a research approach to explore the educators' motives for participating in the B.Ed. Special Education degree programme and the perceived outcomes of the programme in terms of professional development. Descriptive case study is used to describe an intervention or phenomenon and the real-life context in which it occurred (Yin, 2009; Yin, 2003).

\subsection{Research questions}

Three research questions were addressed in the present study. They are:

i. What were the participants' motives for participating in the B.Ed. Special Education programme?

ii. What were the participants' perceived outcomes for participating in the programme in terms of professional development?

iii. What relationship can be found between the participants' motives and perceived outcomes of the programme?

In order to address these research questions, a case study as a research approach to explore the educators' motives for participating in the B.Ed. Special Education degree programme and the perceived outcomes of the programme in terms of professional development was adopted. The study involved 35 participants in the B.Ed. Special Education programme at the Open University of Tanzania. The research group consisted of 19 males and 16 females. The educational backgrounds of the participants were different, but they all followed a similar route to qualify in becoming professionals in the field of special education. Data was collected in three waves by using questionnaires and interviews. The interview was however, the main instrument for data collection. All interview II sessions were recorded with the participants' consent. The recorded materials were transcribed verbatim into a more formal written style in order to make them intelligible. The work of transcribing began immediately at the end of each interview session(s), word for word by the researcher. The majority of the data collected in the study was qualitative and analysed by using thematic content analysis (Miles \& Huberman, 1994). Data was coded and classified according to themes that arose out of the data.

\section{Findings}

The findings of the study revealed that participants expressed motives which were related to job performance, knowledge, skills, academic degree and career. The motives were both intrinsic and extrinsic.

What motivated me to join this programme was the desire to learn more about inclusive education, because I had formerly implemented it in one of the primary schools which gave me a lot of trouble at the beginning. Therefore, I had the anticipation of getting more knowledge about inclusive education. 
In this programme, I wanted to upgrade my level of academic qualifications, get a degree, and improve my working conditions such as promotion.

Furthermore, altruistic motives were expressed by the participants in terms of helping and supporting students with special needs and their communities.

In the school where I am teaching there are students with hearing impairments. After working there for several years, I felt sympathy for the children with disabilities and I decided to join the certificate course in special needs education specializing on hearing impairment.

I wanted to be more confident in the job, to be more competent and to assist the community in special education, especially encouraging parents with special needs children to send their children to school.

In addition, the perceived outcomes were expressed as participants got learned new skills such as guidance and counselling and interaction skills. The participants learned the strategies for creating awareness about persons with disability in the communities. The participants deepened their understanding of disability issues. The outcomes were social as well as societal.

I have been involved in policy matters. Recently, I had the opportunity to contribute to a disability bill, which is going to be debated soon in parliament. I am also compiling an analytical report based on the disability survey which was conducted last year.

I use the knowledge and skills to help the community to understand that these children are part of the community and that these children can participate equally in the community choirs.

The participants' perceived outcomes of the programme portrayed the expressed motives. Overall, the study has contributed to better understanding of the phenomenon of professional development from the perspectives of teachers and educators in special education.

\section{Discussion and conclusions}

The research results in this article are threefold: The B. Ed. Special Education was the first bachelor's degree in special education to be offered in Tanzania. It was a pilot programme carried out by the Open University of Tanzania in collaboration with Åbo Akademi University in Vasa, Finland. Therefore, the programme presents a unique model of professional development in a developing country conducted on a semi-distance mode with face-to-face intensive sessions in a collaborative effort between two universities, one from the south and another from the north. Second, the individual, social and societal factors interact when it comes to explaining why Tanzanian educators in special education choose to pursue a degree programme in special education. Therefore, it is simplistic to draw conclusions on the educators' motives based on one of the three perspectives. Third, the study contributes to increased understanding of the complexity of professional development and of the realities educators meet when educational reforms are implemented in a developing country. 
Overall, the Tanzanian teachers and educators motives for participating in the programme and their perceived outcomes are not unique. Motives like the desire for more knowledge and skills, career advancement and promotion, better pay and remuneration are similar across educators and teachers worldwide. Earlier studies expose similar motives and outcomes expressed by educators and teachers in other parts of the world. The implementation of education for all cannot be attained and sustained without professional development for teachers and educators. Therefore, investing on professional development should be considered as a strategy towards realizing the education for all goals. Teacher education should respond accordingly to this call.

To conclude, it is worth noting that the individual, social and societal factors interact when it comes to explaining why Tanzanian educators in special education choose to pursue a degree programme in special education. Thus, it is simplistic to draw conclusions on the educators' motives based on one of the three perspectives. The study contributes to increased understanding of the complexity of professional development phenomenon and of the realities educators meet when educational reforms are implemented in a developing country. Overall, the Tanzanian teachers and educators' motives for participating in the programme and their perceived outcomes are not unique. Earlier studies expose similar motives and outcomes expressed by teachers and educators in other parts of the world. Finally, the implementation of education for all cannot be attained and sustained without professional development for teachers and educators in special education. Therefore, investing in various forms of professional development should be considered as a strategy towards realizing the education for all as a global and local phenomenon. Teacher education should respond accordingly in realizing this goal.

\section{References}

Deci, E. L. (1971). Effects of externally mediated rewards on intrinsic motivation. Journal of Personality and Social Psychology, 18, 105-115. http://dx.doi.org/10.1037/h0030644

Deci, E. L. (1975). Intrinsic motivation. New York: Plenum. http://dx.doi.org/10.1007/978-1-4613-4446-9

Deci, E. L., \& Ryan, R. M. (1985). The general causality orientations scale: Self-determination in personality. Journal of Research in Personality, 19, 109-134. http://dx.doi.org/10.1016/0092-6566(85)90023-6

Deci, E. L., \& Ryan, R. M. (2002). Handbook of self-determination research. Rochester, NY: University of Rochester Press.

Giroux, H. A. (2004). Critical pedagogy and the postmodern/modern divide: Towards a pedagogy of democratisation. Teacher Education Quarterly, 2004, 31-47.

Howe, A. C., \& Stubbs, H. S. (1996). Empowering science teachers: A model for professional development. Journal of Science Teacher Education, 8(3), 167-182. http://dx.doi.org/10.1023/A:1009487417488 
Kalanje, E. S. (2011). Identification of First Graders at Risk of Reading and Writing Difficulties Creating a Group-Based Screening Tool in Kiswahili in Tanzania. Vasa: Abo Akademi University Press

Levesque, C., Copeland, K. J., \& Sutcliffe, R. A. (2008). Conscious and nonconscious processes: Implications of Self-Determination Theory. Canadian Psychology, 49(3), 218-224. http://dx.doi.org/10.1037/a0012756.

Mboya, M., \& Mosha, E. J. (2003). Baseline survey on situation of the disabled in Tanzania: An activity report leading to the implementation of programs of the 'Africa decade of Disabled People in Tanzania 2000-2009. Dar es Salaam: SHYVYAWATA.

Miles, M. B., \& Huberman, A. M. (1994). Qualitative data analysis: An expanded sourcebook( $2^{\text {nd }}$ Edition.). Thousand Oaks: Sage Publications.

MoEC. (2001). Education Sector Development Programme: Primary Education Development Plan (2002-2006). Dar es Salaam: Ministry of Education and Culture.

MoEC. (2004). Secondary Education Development Plan 2004-2009: Final document. Dar es Salaam: Ministry of Education and Culture.

MoEVT. (2006). Education and Training Sector Development Programme: Primary Education Development Programme II (2007-2011). Dar es Salaam: Ministry of Education and Vocational Training.

MoEVT. (2010). Basic Education Statistics in Tanzania: National Data. Dar es Salaam: Ministry of Education and Vocational Training.

MoEVT. (2011). Basic Education Statistics in Tanzania: National Data. Dar es Salaam: Ministry of Education and Vocational Training.

MoEVT. (2012). Basic Education Statistics in Tanzania: National Data. Dar es Salaam: Ministry of Education and Vocational Training.

MoEVT. (2013). Basic Education Statistics in Tanzania: National Data. Dar es Salaam: Ministry of Education and Vocational Training.

Okkolin, M-A., Lehtomäki, E., \& Bhalalusesa, E. (2010). The successful education sector development in Tanzania- comment on gender balance and inclusive education. Gender and Education, 22(1), 63-71. http://dx.doi.org/10.1080/09540250802555416.

Ryan, R. M., \& Deci, E. L. (2000). Self-determination theory and the facilitation of intrinsic motivation, social development and well-being. American Psychologist, 55(1), 68-78. http://dx.doi.org/10.103//0003-066X.55.1.68.

URT. (2008). Tanzania 2008 Disability Survey Report. Dar es Salaam: NBS.

URT. (2012). 2012 Population and Housing Census: Population Distribution by Administrative Areas. Downloaded at http://www.nbs.go.tz/sensa/new.html on $1^{\text {st }}$ August 2013 at 10:17 am. 


\section{Macrothink}

International Journal of Education

ISSN 1948-5476

2014, Vol. 6, No. 4

Yin, R. K. (2003). Case study research: Design and methods ( $3^{\text {rd }}$ Edition.). Thousand Oaks: Sage Publications.

Yin, R. K. (2009). Case study research: Design and methods, ( $4^{\text {th }}$ Edition.). Thousand Oaks: Sage.

Note

Note 1. Downloaded from http://www.nbs.go.tz/ on 10th June 2013 at 9:19pm.

\section{Copyright Disclaimer}

Copyright for this article is retained by the author(s), with first publication rights granted to the journal.

This is an open-access article distributed under the terms and conditions of the Creative Commons Attribution license (http://creativecommons.org/licenses/by/3.0/). 